(2) Open Access Full Text Article

REVIEW

\title{
Anamorelin hydrochloride in the treatment of cancer anorexia-cachexia syndrome: design, development, and potential place in therapy
}

This article was published in the following Dove Press journal:

Drug Design, Development and Therapy

7 August 2017

Number of times this article has been viewed

\author{
Solomon A Graf ${ }^{1-3}$ \\ Jose M Garcia ${ }^{4,5}$ \\ 'Veterans Affairs Puget Sound \\ Health Care System, ${ }^{2}$ Department \\ of Medicine, Division of Medical \\ Oncology, University of Washington \\ School of Medicine, ${ }^{3}$ Clinical \\ Research Division, Fred Hutchinson \\ Cancer Research Center, ${ }^{4}$ Geriatric \\ Research, Education and Clinical \\ Center, Veterans Affairs Puget Sound \\ Health Care System, ${ }^{5}$ Department of \\ Medicine, Division of Gerontology \\ and Geriatric Medicine, University \\ of Washington School of Medicine, \\ Seattle, WA, USA
}

\begin{abstract}
Cancer anorexia-cachexia syndrome (CACS) is a complex and largely untreatable paraneoplastic complication common in advanced cancer. It is associated with profoundly deleterious effects on quality of life and survival. Since its discovery over a decade ago, anamorelin hydrochloride (anamorelin), a mimetic of the growth hormone secretagogue ghrelin, has shown considerable promise in ameliorating components of CACS when administered to patients with advanced cancer, including loss of lean body mass and reversal of anorexia. This review summarizes the development of anamorelin and its safety and efficacy in clinical investigations. The potential future role of anamorelin in treating CACS is also discussed.
\end{abstract}

Keywords: anamorelin, cachexia, anorexia, ghrelin, non-small cell lung cancer

\section{Introduction}

Anorexia and cachexia are long-recognized hallmarks of advanced illness. In patients with cancer, the anorexia-cachexia syndrome (CACS) describes a multifactorial syndrome characterized by an ongoing loss of skeletal muscle mass (with or without loss of fat mass) that cannot be fully reversed by conventional nutritional support and leads to progressive functional impairment. ${ }^{1,2}$ The pathologic mechanisms responsible for CACS are incompletely understood. ${ }^{3,4}$ Recent studies in murine models have identified molecular and enzymatic pathways that appear to drive cachexia, including, for example, signaling via Fn14 (tumor necrosis factor receptor superfamily member 12A) and tumor necrosis factor-related weak inducer of apoptosis (TWEAK), ${ }^{5-7}$ inactivation of $5^{\prime}$ adenosine monophosphate-activated protein kinase leading to futile energy wasting by white adipose tissue, ${ }^{8}$ and the role of parathyroid hormone-related peptide mediating hypermetabolism. ${ }^{9}$ The complexity of factors underlying CACS is reflected in the diversity in its clinical manifestations and outcomes. ${ }^{7}$

CACS is a progressive wasting condition: its severity is classified along a spectrum from precachexia to cachexia to refractory cachexia ${ }^{2}$ and is typically measured by percentage weight or muscle mass loss in the context of body mass index (BMI). ${ }^{10}$ While CACS is gaining recognition as an important entity in oncology practice, it likely remains underdiagnosed ${ }^{11}$ and often goes untreated. ${ }^{2,10,12}$ CACS can be associated with cancer treatment resistance, psychosocial distress in patients and their families, loss of quality of life, and decreased overall survival. ${ }^{13}$ Trials evaluating CACS therapies must account for these complexities and evaluate clinically meaningful endpoints. Regulatory agencies, including the US Food and Drug Administration (FDA) and
Correspondence: Jose M Garcia Geriatric Research, Education and Clinical Center, Veterans Affairs Puget Sound Health Care System, University of Washington, 1660 South Columbian Way (S-I82-GRECC), Seattle, WA 98108I597, USA

Tel +I 2067642984

Fax + I 2067642569

Email jose.garcia@va.gov (c) (1) (5) 2017 Graf and Garcia. This work is published and licensed by Dove Medical Press Limited. The full terms of this license are available at https://www.dovepress.com/terms.php cc) hereby accept the Terms. Non-commercial uses of the work are permitted without any further permission from Dove Medical Press Limited, provided the work is properly attributed. For permission for commercial use of this work, please see paragraphs 4.2 and 5 of our Terms (https://www.dovepress.com/terms.php). 
the European Medicines Agency have yet to coalesce on accepted parameters in the design of clinical trials evaluating CACS interventions. ${ }^{14}$

Modern approaches to CACS acknowledge the syndrome's complexity and attempt to address any modifiable factors, including the underlying cancer. ${ }^{15}$ The National Comprehensive Cancer Network guidelines, for example, advocate for a comprehensive assessment of potential causes of anorexia and cachexia and corresponding interventions, including pharmacologic treatment of depression and impaired gastric motility and digestion, institution of an exercise program, and consideration of nutrition consultation and support and, in certain cases, pharmacologic appetite stimulation. ${ }^{16}$ The guidelines additionally stress active focus on patient goals and preferences in addition to education of the patient and family on the natural history of CACS in terminally ill patients. Some single-center clinical studies have shown the benefit of multiagent regimens including progestins, antiinflammatory and antioxidant agents, and immunomodulation in combination. ${ }^{17,18}$ However, this approach has not been validated in larger placebo-controlled studies, and no treatment is currently FDA approved for the prevention or treatment of cachexia. Therefore, improved treatment options for CACS remain an important unmet clinical need.

CACS incidence varies across cancer types, afflicting $>50 \%$ of patients with advanced lung cancer and upward of $80 \%$ of patients with advanced gastrointestinal cancers. ${ }^{19}$ CACS is influenced by the stage of cancer, the efficacy of anticancer therapy, the impact of the cancer on gastrointestinal function, and cancer treatments themselves. Much of the clinical research in CACS has been performed in patients with non-small cell lung cancer (NSCLC) as it is a relatively common cancer with a high prevalence of CACS. The mainstay of therapy for most patients with advanced NSCLC includes systemic anticancer chemo- and immunotherapies given to slow disease progression and optimize the quality of life. Improvements in the understanding of NSCLC biology, with respect to both its mutational profile and interaction with host immunity, have, fortunately, resulted in meaningful improvements in outcomes of this disease over the past few years. In addition, early involvement of palliative care, with its focus on patient symptoms, including CACS, has emerged as a key component of NSCLC care. ${ }^{20}$ Nevertheless, advanced stage NSCLC remains incurable, and CACS, therefore, continues to be a prominent and largely untreatable complication of the disease.

Anamorelin hydrochloride (referred to subsequently as anamorelin) is a novel pharmaceutical that has generated considerable excitement for its potential to treat CACS, including in patients with advanced NSCLC. Here, we review its preclinical development and summarize recent data on its use treating CACS patients.

\section{Design and development The ghrelin system}

Ghrelin, a 28-amino acid peptide hormone secreted primarily by the stomach, is a key modulator of energy homeostasis and growth hormone $(\mathrm{GH})$ secretagogue. ${ }^{21}$ It crosses the blood-brain barrier and engages a $\mathrm{G}$ protein-coupled receptor in the hypothalamic nuclei regulating energy expenditure and food intake. ${ }^{22}$ This receptor is also expressed in other tissues in the periphery, although it is not expressed in the liver, skeletal muscle, or adipose tissue. ${ }^{23}$ Several studies have suggested that not all the effects of ghrelin are mediated through this receptor, although the alternative receptor has not yet been characterized. ${ }^{24,25}$ The ghrelin system is a focus of pharmacologic research in $\mathrm{GH}$ secretion, ${ }^{26}$ obesity, ${ }^{27}$ intestinal dysmotility, ${ }^{28}$ and cachexia.

Animal studies have shown that intravenous administration of ghrelin improved the markers of nutrition, including food intake, adiposity, and lean body mass and muscle strength. ${ }^{29}$ In models of cancer cachexia as well as sepsis, ghrelin also was shown to decrease inflammation. ${ }^{24,30}$ In small studies, ghrelin has shown promise as a single-agent therapy delivered intravenously to patients with CACS, some of whom were actively receiving highly emetogenic chemotherapy. Treatment was well tolerated, and improvement in food intake, appetite, and nausea related to ongoing chemotherapy was observed. ${ }^{31,32}$ Ghrelin also showed encouraging results by improving appetite, lean body mass, and exercise capacity in small studies of patients with cachexia due to congestive heart failure and chronic obstructive pulmonary disease. ${ }^{33-35}$

\section{Anamorelin development}

Though promising in its potential for treating CACS, the administration of ghrelin is cumbersome in everyday clinical practice due to its parenteral formulation and $\sim 30$-minute halflife. Other approaches to targeting the ghrelin system have therefore been pursued. Although ghrelin was only identified in 1999 as the endogenous ligand of the ghrelin receptor, ${ }^{36}$ agonists of the ghrelin receptor have been in clinical development since 1981. ${ }^{37}$ Anamorelin (formerly known as ONO7643 and RC-1291) is a synthetic mimetic of the N-terminal active core of ghrelin. It was developed by Novo Nordisk in 1999 and was subsequently licensed to Ono and Helsinn Therapeutics for the treatment of cachexia and anorexia in 
cancer patients. ${ }^{38}$ It is orally available and has a half-life of $\sim 7$ hours, making it an attractive candidate for modulating the ghrelin axis..$^{39}$ Radiolabeled drug experiments showed that anamorelin is excreted predominantly in feces (92\%) and to a small degree in urine ( $8 \%$ ). In a Phase I study involving 24 healthy volunteers, a fixed 25-mg dose of anamorelin resulted in higher plasma concentrations in women compared with men, with area under the concentration-time curve from zero to infinity $\sim 1.9$-fold higher in women. ${ }^{40}$ No corresponding relationship was seen in GH levels, however, and subsequent, unpublished, data indicated that higher doses of $100 \mathrm{mg}$ resulted in no difference in plasma concentrations between men and women.

\section{Preclinical data}

In cultured cell lines, anamorelin has a half-maximal effective concentration value for agonist activity on the ghrelin receptor of 0.74 nanomolar. ${ }^{41}$ In a lung cancer xenograft mouse model, anamorelin had no impact on the rate of in vivo tumor growth, and no signals of treatment-related toxicities were observed at all doses tested, up to $30 \mathrm{mg} / \mathrm{kg}$. ${ }^{42}$ In rats, administration of anamorelin at single oral doses of 3,10 , and $30 \mathrm{mg} / \mathrm{kg}$ resulted in a dose-dependent response of increasing plasma concentrations of $\mathrm{GH}$, and once-daily dosing caused increases in both food intake and body weight during the first week of treatment. ${ }^{41}$ Pharmacodynamic studies subsequently showed that increases in circulating GH peaked $\sim 1$ hour after the dose, and the magnitude of the effect fell off after several days of treatment. ${ }^{43}$ Off-target effects on anterior pituitary hormone axes, including prolactin, luteinizing hormone, folliclestimulating hormone, thyroid-stimulating hormone, adrenocorticotropic hormone, and cortisol, were not observed, and no evidence of significant effect on carbohydrate metabolism was found, confirming the relatively selective effect in the pituitary of anamorelin on GH regulation.

\section{Clinical data}

Early clinical study of anamorelin included its evaluation in a single-center, randomized, double-blind, placebo-controlled, dose-escalation Phase I study in 32 healthy volunteers. ${ }^{44}$ Subjects were initially administered $25 \mathrm{mg}$ anamorelin daily for 5 days, with subsequent cohorts given $50 \mathrm{mg}$ daily (single or divided dosing) and $75 \mathrm{mg}$ once daily. Significant increase in body weight was observed in patients that were administered 50 or $75 \mathrm{mg}$ daily, with a mean increase in weight from baseline to day 6 of $1.25 \pm 0.725 \mathrm{~kg}(P=0.0022$ versus placebo) in the cohort that received $50 \mathrm{mg}$ daily and $1.16 \pm 0.651 \mathrm{~kg}(P=0.0022$ versus placebo $)$ in those that received $75 \mathrm{mg}$ daily. There was no increase in body weight changes in subjects given $25 \mathrm{mg}$ twice a day compared with those given $50 \mathrm{mg}$ once a day. No significant adverse events thought related to the study drug were noted except for a single case of moderately elevated transaminases that normalized after discontinuation of the drug. ${ }^{44}$

In a pilot Phase II randomized, double-blind, placebocontrolled crossover study across 7 sites in the USA, anamorelin was given to 16 patients with various incurable cancers, 7 of whom had NSCLC and CACS. ${ }^{45}$ Patients were treated with $50 \mathrm{mg}$ daily or placebo for 3 days followed by a day 3 through 7 washout followed by switching of treatments. In this relatively small study with a brief intervention, 3 days of anamorelin resulted in increased mean body weight ( $0.77 \mathrm{~kg}$ versus negative $0.33 \mathrm{~kg}, P=0.016)$ and numerical improvement in patient-reported symptoms and appetite; the study was not powered to confirm such effects. Body composition was not assessed, and objective measures of patient function were not performed. Hyperglycemia was observed in 2 patients and attributed to anamorelin. ${ }^{45}$

Two larger, Phase II, randomized, double-blind, placebocontrolled studies were performed at 20 sites in the USA, and their results were pooled a priori and reported together. ${ }^{46}$ A total of 82 patients were treated, and in both studies, patients were required to have advanced or incurable histologically confirmed cancer and CACS. Exclusion criteria included transaminases greater than twice the upper limit of normal, diabetes, ascites or edema that could affect weight assessment, and body mass index of $>30 \mathrm{~kg} / \mathrm{m}^{2}$. Patients were randomized after stratification by weight-loss severity $(5 \%-15 \%$ versus $>15 \%$ ) and those in the treatment arm given anamorelin $50 \mathrm{mg}$ daily for up to 12 weeks. Patients had a variety of underlying malignancies, including lung $(N=20)$, colorectal $(N=17)$, and genitourinary $(N=13)$, and the majority $(80 \%)$ were receiving concurrent chemotherapy. One hundred and two patients were screened and 82 were treated. Attrition during the study was relatively high, but accounted in the a priori statistical design in this population of patients with advanced cancer: of the 44 patients assigned to anamorelin, 21 discontinued treatment (12 due to patient preference) before the planned completion of therapy; of the 38 patients assigned to placebo, 15 discontinued treatment (6 due to patient preference) before the planned completion of therapy. Compared with placebo, patients treated with anamorelin had an improvement in mean lean body mass at 12 weeks; the primary endpoint of the study is as follows: increase of $1.89 \mathrm{~kg}$ (95\% confidence interval [CI]: 0.84-2.95) versus decrease of $0.20 \mathrm{~kg}(95 \% \mathrm{CI}:-1.23$ to 0.83$), P=0.0006$. 
In addition, results favored anamorelin with regard to secondary endpoints, including total body mass but not fat mass, nondominant hand grip strength, and patient quality of life, particularly in the domains of sense of well-being, sleep, nausea, and drowsiness. Anamorelin also significantly increased $\mathrm{GH}$ levels and biomarkers of protein synthesis insulin-like growth factor-1 (IGF-1) and insulin-like growth factor-binding protein 3 (IGFBP-3) after 3 days of treatment. Though anamorelin was very well tolerated, it was noted that mean glucose and insulin concentrations were modestly increased with anamorelin versus placebo (differences of $0.95 \mathrm{mmol} / \mathrm{L}$ for glucose $[P=0.0002]$ and $77.92 \mathrm{pmol} / \mathrm{L}$ for insulin $[P=0.0031])$. While this did not have an appreciable impact on the rate of hyperglycemia, patients with diabetes or obesity were excluded from the study.

Another Phase II, randomized, double-blind, placebocontrolled study was conducted at 32 sites in Japan and recently published. ${ }^{47}$ The study design included a 2-week observation/ run-in period prior to treatment. Subjects with inoperable or relapsed stage III or IV NSCLC were required to have at least $5 \%$ involuntary weight loss over the past 6 months in addition to clinical and biochemical markers of cachexia. Patients were randomized to $3 \mathrm{arms}$ and received 50 or $100 \mathrm{mg}$ of anamorelin or placebo once daily for 12 weeks, and change in lean body mass measured by dual-energy X-ray absorptiometry and nondominant handgrip strength were the 2 coprimary endpoints. One hundred and eighty-one patients were enrolled between March 2011 and September 2012. Of these, only 115 patients were included in the final "per-protocol set" that was analyzed. The 66 patients not in the final analysis were excluded primarily due to treatment discontinuation within 6 weeks of randomization or protocol violations, including receipt of prohibited concomitant treatments such as certain cancer therapies, systemic corticosteroids, and numerous other prescription and supplemental medications. The 36\% rate of exclusion from the per-protocol set was higher than the $20 \%$ rate originally anticipated and required an increase in the planned sample size. In the per-protocol set, $\geq 96 \%$ of patients took $\geq 80 \%$ of allocated study drug. Lean body mass at 12 weeks increased in all the 3 groups; the reason for this result in the placebo group was not clear. The difference compared with placebo was statistically significant in the $100 \mathrm{mg}$ treatment arm, with a net increase of $0.6 \mathrm{~kg}$ (95\% CI: $0.00-1.21, P=0.05)$. The increase in lean body mass was not statistically different between the placebo and $50 \mathrm{mg}$ treatment arms. No difference in handgrip strength was observed among the 3 arms. Secondary endpoints, including quality-of-life assessments and body weight, in addition to markers of muscle protein synthesis IGF-1 and IGFBP-3, were also improved in the $100 \mathrm{mg}$ treatment arm but not in the $50 \mathrm{mg}$ arm compared with placebo. Treatment with anamorelin was generally well tolerated but associated with increased nausea $(31 \%$ in $100 \mathrm{mg}$ treatment arm versus $9 \%$ in $50 \mathrm{mg}$ treatment arm and $17 \%$ in placebo arm) and blood glucose, as measured by hemoglobin A1c (20\% with increased glycosylated hemoglobin in $100 \mathrm{mg}$ treatment arm versus $6 \%$ in $50 \mathrm{mg}$ treatment arm and $0 \%$ in placebo).

Promising results from these early phase clinical trials led to ROMANA 1 and ROMANA 2, two international, randomized, double-blind, placebo-controlled Phase III pivotal studies of anamorelin in patients with advanced NSCLC. ${ }^{48}$ The majority of patients were recruited at sites in Ukraine, Poland, Russia, and Hungary. In all, 54 sites in 15 countries participated in ROMANA 1 and 39 sites in 7 countries participated in ROMANA 2. Patients were randomized 2:1 to receive $100 \mathrm{mg}$ anamorelin or placebo once daily for a 12-week study period. Inclusion criteria were a life expectancy of at least 4 months, unresectable stage III or IV NSCLC, and CACS defined as involuntary weight loss of at least $5 \%$ within the previous 6 months or body mass index of $<20 \mathrm{~kg} / \mathrm{m}^{2}$. Outcomes included the coprimary endpoints of change in lean body mass and nondominant handgrip strength as well as secondary endpoints of overall survival, change from baseline in body weight, and symptoms of anorexia-cachexia and fatigue. The calculated sample size of 477 accounted for an anticipated dropout rate of 30\% and was designed with a $90 \%$ power to detect a change of $2.0 \mathrm{~kg}$ from baseline over 12 weeks in both lean body mass and handgrip strength. ROMANA 1 enrolled 484 patients between July 2011 and January 2014; ROMANA 2 enrolled 495 patients between July 2011 and October 2013.

Planned treatment was completed in $74 \%$ and $72 \%$ of patients in ROMANA 1 and ROMANA 2, respectively; 19\% and $14 \%$ died during the 12 -week study period, respectively. The majority received anticancer therapy during the study, including $>70 \%$ of patients in ROMANA 1 and $>60 \%$ of patients in ROMANA 2 concurrently treated with a platinumbased chemotherapy doublet. Post hoc analyses revealed that patients treated in ROMANA 2 had more advanced cancer, with a longer time from diagnosis to study entry, worse performance status, lower rate of ongoing cancer therapy, and more severe markers of cachexia, including lower lean body mass and symptom burden.

Median lean body mass increased in the anamorelin treatment groups compared with placebo in both ROMANA 1 (0.99 kg, 95\% CI: $0.61-1.36$ versus $-0.47 \mathrm{~kg}, 95 \%$ CI: -1.00 
to $0.21 ; P<0.0001)$ and ROMANA $2(0.65 \mathrm{~kg}, 95 \% \mathrm{CI}: 0.38$ 0.91 versus $-0.98 \mathrm{~kg}, 95 \% \mathrm{CI}:-1.49$ to $-0.41 ; P<0.0001)$ and was consistently observed across subgroups. Median handgrip strength was unchanged in both studies. In the subgroup of men treated in ROMANA 1, median handgrip strength was improved in the anamorelin arm: $-0.76 \mathrm{~kg}, 95 \% \mathrm{CI}:-1.56$ to -0.11 versus $-2.51 \mathrm{~kg}, 95 \% \mathrm{CI}:-3.96$ to $-1.37 ; P=0.024$. Treatment with anamorelin resulted in increased mean body weight and improvement in mean anorexia-cachexia symptoms from baseline over 12 weeks. In both cases, improvement was apparent at week 3 of treatment and sustained throughout the study period. Median survival at 1 year was no different between study groups. Treatment-related adverse events were uncommon, mild, and similar to those previously reported. They included grade 1-2 hyperglycemia (5\% in anamorelin arm versus 3\% in placebo arm in ROMANA 1; 4\% in anamorelin arm versus $1 \%$ in placebo arm in ROMANA 2) and grade $1-2$ gastrointestinal disorders $(6 \%$ in anamorelin arm versus $2 \%$ in placebo arm in ROMANA $1 ; 2 \%$ in anamorelin arm versus $2 \%$ in placebo arm in ROMANA 2$).{ }^{48}$

ROMANA 3 (NCT01395914) is an ongoing extension study of ROMANA 1 and ROMANA 2, and is designed to further evaluate the safety and tolerability of anamorelin. Patients who completed a day 85 visit in the pivotal trials and were considered appropriate to continue receiving additional study drug were eligible to enroll. A target enrollment of 345 subjects was planned and the publication of results from ROMANA 3 are awaited.

Anamorelin is also being studied for its potential impact on cancer-related fatigue. In a single arm, Phase II study led by the MD Anderson Cancer Center (NCT03035409), anamorelin will be administered at $100 \mathrm{mg}$ daily for 6 weeks to patients with advanced cancer. The primary endpoint of difference in Functional Assessment of Cancer Illness Therapy-Fatigue Subscale Score will be measured at baseline versus day 43 in a target cohort of 38 patients; multiple metrics will be used for additional assessments of physical activity.

\section{Conclusion}

Anamorelin has shown clear benefit on multiple markers of CACS due to NSCLC and other malignancies. Across studies, it has consistently resulted in positive impact on lean body mass, total body weight, appetite, and quality-of-life metrics when administered over a period of days to up to several months (Table 1). It is well tolerated overall, with occasional toxicities of mild gastrointestinal symptoms and hyperglycemia, and shows no effect on cancer progression or treatment efficacy. Despite these notable attributes and potential benefit to patients with CACS, anamorelin fell short in meeting the coprimary endpoint measuring functional status by handgrip strength in its evaluation in 2 pivotal Phase III studies. This result illustrates the difficulty in measuring the impact of a single intervention in a multifactorial and complex syndrome. Handgrip strength was improved in smaller Phase II studies and, ${ }^{46}$ indeed, in the subset of men in ROMANA 1, but not in the overall study population. ${ }^{48}$ The reasons for this discrepancy cannot be determined from the available data but may include differences in the study design (such as the dose of anamorelin used) or the patient population (all tumors versus NSCLC; US versus international, etc.). Given that there is no consensus on what the best measure of function should be in this setting, it is unclear if other tools (ie, stair climbing power, actigraphy, 6-minute walk test) would have responded differently.

By definition, studies investigating interventions for CACS treat patients nearing the end of their lives and coping

Table I Summary of published clinical trials of anamorelin hydrochloride

\begin{tabular}{|c|c|c|c|c|c|c|}
\hline Reference & $\begin{array}{l}\text { Year } \\
\text { reported }\end{array}$ & Subjects & Treatment & Study type & $\begin{array}{l}\text { Number } \\
\text { of subjects }\end{array}$ & Key results \\
\hline $\begin{array}{l}\text { Garcia and } \\
\text { Polvino }{ }^{44}\end{array}$ & 2007 & $\begin{array}{l}\text { Healthy } \\
\text { volunteers }\end{array}$ & $\begin{array}{l}\text { Escalating doses of } \\
\text { anamorelin (up to } \\
75 \text { mg daily) } \times 5 \text { days }\end{array}$ & Phase I, randomized & 32 & $\begin{array}{l}\text { Increase in total body } \\
\text { weight; no major AEs }\end{array}$ \\
\hline Garcia et $\mathrm{al}^{45}$ & 2013 & Advanced cancers & $\begin{array}{l}50 \mathrm{mg} \text { daily of } \\
\text { anamorelin } \times 3 \text { days }\end{array}$ & $\begin{array}{l}\text { Pilot Phase II, } \\
\text { randomized, crossover }\end{array}$ & 16 & Increase in total body weight \\
\hline Garcia et $\mathrm{al}^{46}$ & 2015 & Advanced cancers & $\begin{array}{l}50 \mathrm{mg} \text { daily of } \\
\text { anamorelin } \times 12 \text { weeks }\end{array}$ & $\begin{array}{l}\text { Two Phase II, randomized } \\
\text { (results pooled a priori) }\end{array}$ & 82 & $\begin{array}{l}\text { Increase in LBM and } \\
\text { secondary endpoints of HGS } \\
\text { and multiple QOL metrics }\end{array}$ \\
\hline Takayama et $\mathrm{al}^{47}$ & 2016 & Advanced cancers & $\begin{array}{l}50 \text { or } 100 \mathrm{mg} \text { daily } \\
\text { anamorelin } \times 12 \text { weeks }\end{array}$ & Phase II, randomized & 181 & $\begin{array}{l}\text { Increase in LBM but not } \\
\text { coprimary endpoint of HGS }\end{array}$ \\
\hline Temel et $\mathrm{al}^{48}$ & 2016 & Advanced NSCLC & $\begin{array}{l}100 \mathrm{mg} \text { daily } \\
\text { anamorelin } \times 12 \text { weeks }\end{array}$ & $\begin{array}{l}\text { Two Phase III, } \\
\text { randomized }(2: 1)\end{array}$ & 484 and 495 & $\begin{array}{l}\text { Increase in LBM but not } \\
\text { coprimary endpoint of HGS }\end{array}$ \\
\hline
\end{tabular}

Abbreviations: AE, adverse event; HGS, hand grip strength; LBM, lean body mass; NSCLC, non-small cell lung cancer; QOL, quality of life. 
with profound challenges in multiple domains, including the physical, psychosocial, and economic. Participation by such patients in clinical protocols can prove prohibitively burdensome, especially when efficacy measurements fall outside the realm of standard clinical care as is the case for CACS treatments. Work is therefore underway to streamline the definition and relevant treatment outcomes of CACS. Therefore, successful mitigation of CACS undoubtedly requires multipronged treatment approaches that individually target contributing components, including metabolic and inflammatory pathways, mental health, nutrition, physical fitness, and the cancer itself and its treatment. Future work should explore the effects of combining anamorelin with other pharmacologic interventions targeting depression and anxiety, as indicated, and intensive efforts to optimize nutrition and fitness.

\section{Acknowledgments}

This work was funded by the US Department of Veterans Affairs (MERIT grants BX002807 and CX000174) and the National Institutes of Health grant AG040583 to JMG. We thank the University of Washington Diabetes and Endocrinology Research Center (P30 DK017047) and Nutrition Obesity Research Center (P30 DK035816) for their help.

\section{Disclosure}

JMG is a consultant for Helsinn Theraputics, Inc. The authors report no other conflicts of interest in this work.

\section{References}

1. Evans WJ, Morley JE, Argilés J, et al. Cachexia: a new definition. Clin Nutr. 2008;27(6):793-799.

2. Fearon K, Strasser F, Anker SD, et al. Definition and classification of cancer cachexia: an international consensus. Lancet Oncol. 2011;12(5): 489-495.

3. Mondello $\mathrm{P}$, Mian M, Aloisi C, Famà F, Mondello S, Pitini V. Cancer cachexia syndrome: pathogenesis, diagnosis, and new therapeutic options. Nutr Cancer. 2015;67(1):12-26.

4. Bruggeman AR, Kamal AH, LeBlanc TW, Ma JD, Baracos VE, Roeland EJ. Cancer cachexia: beyond weight loss. J Oncol Pract. 2016; 12(11):1163-1171.

5. Johnston AJ, Murphy KT, Jenkinson L, et al. Targeting of Fn14 Prevents Cancer-Induced Cachexia and Prolongs Survival. Cell. 2015; 162(6):1365-1378.

6. Schafer M, Oeing CU, Rohm M, et al. Ataxin-10 is part of a cachexokine cocktail triggering cardiac metabolic dysfunction in cancer cachexia. Mol Metab. 2016;5(2):67-78.

7. Petruzzelli M, Wagner EF. Mechanisms of metabolic dysfunction in cancer-associated cachexia. Genes Dev. 2016;30(5):489-501.

8. Rohm M, Schäfer M, Laurent V, et al. An AMP-activated protein kinasestabilizing peptide ameliorates adipose tissue wasting in cancer cachexia in mice. Nat Med. 2016;22(10):1120-1130.

9. Kir S, Komaba H, Garcia AP, et al. PTH/PTHrP receptor mediates cachexia in models of kidney failure and cancer. Cell Metab. 2016;23(2): 315-323.
10. Martin L, Senesse P, Gioulbasanis I, et al. Diagnostic criteria for the classification of cancer-associated weight loss. J Clin Oncol. 2015; 33(1):90-99.

11. Davis MP, Dickerson D. Cachexia and anorexia: cancer's covert killer. Support Care Cancer. 2000;8(3):180-187.

12. Vanhoutte G, van de Wiel M, Wouters K, et al. Cachexia in cancer: what is in the definition? BMJ Open Gastroenterol. 2016;3(1):e00097.

13. Garber K. Cancer anabolic metabolism inhibitors move into clinic. Nat Biotechnol. 2016;34(8):794-795.

14. Fearon $\mathrm{KCH}$, Argiles JM, Baracos VE, et al. Request for regulatory guidance for cancer cachexia intervention trials. J Cachexia Sarcopenia Muscle. 2015;6(4):272-274.

15. Mantovani G, Madeddu C, Maccio A. Drugs in development for treatment of patients with cancer-related anorexia and cachexia syndrome. Drug Des Devel Ther. 2013;7:645-656.

16. Levy M, Smith T, Alvarez-Perez A, et al. Palliative care version 1.2016. J Natl Compr Canc Netw. 2016;14(1):82-113.

17. Mantovani G, Macciò A, Madeddu C, et al. Randomized phase III clinical trial of five different arms of treatment in 332 patients with cancer cachexia. Oncologist. 2010;15(2):200-211.

18. Maccio A, Madeddu C, Gramignano G, et al. A randomized phase III clinical trial of a combined treatment for cachexia in patients with gynecological cancers: evaluating the impact on metabolic and inflammatory profiles and quality of life. Gynecol Oncol. 2012;124(3):417-425.

19. von Haehling S, Anker MS, Anker SD. Prevalence and clinical impact of cachexia in chronic illness in Europe, USA, and Japan: facts and numbers update 2016. J Cachexia Sarcopenia Muscle. 2016;7(5): 507-509.

20. Temel JS, Greer JA, Muzikansky A, et al. Early palliative care for patients with metastatic non-small-cell lung cancer. $N$ Engl J Med. 2010;363(8):733-742.

21. Cui H, Lopez M, Rahmouni K. The cellular and molecular bases of leptin and ghrelin resistance in obesity. Nat Rev Endocrinol. 2017; 13(6):338-351.

22. Al Massadi O, López M, Tschöp M, Diéguez C, Nogueiras R. Current Understanding of the Hypothalamic Ghrelin Pathways Inducing Appetite and Adiposity. Trends Neurosci. 2017;40(3):167-180.

23. Sun Y, Garcia JM, Smith RG. Ghrelin and growth hormone secretagogue receptor expression in mice during aging. Endocrinology. 2007; 148(3): 1323-1329.

24. Chen JA, Splenser A, Guillory B, et al. Ghrelin prevents tumour- and cisplatin-induced muscle wasting: characterization of multiple mechanisms involved. J Cachexia Sarcopenia Muscle. 2015;6(2):132-143.

25. Porporato PE, Filigheddu N, Reano S, et al. Acylated and unacylated ghrelin impair skeletal muscle atrophy in mice. J Clin Invest. 2013; 123(2):611-622.

26. Garcia JM, Swerdloff R, Wang C, et al. Macimorelin (AEZS-130)stimulated growth hormone $(\mathrm{GH})$ test: validation of a novel oral stimulation test for the diagnosis of adult GH deficiency. J Clin Endocrinol Metab. 2013;98(6):2422-2429.

27. Foster-Schubert KE, Cummings DE. Emerging therapeutic strategies for obesity. Endocr Rev. 2006;27(7):779-793.

28. Hasler WL. Emerging drugs for the treatment of gastroparesis. Expert Opin Emerg Drugs. 2014;19(2):261-279.

29. DeBoer MD, Zhu XX, Levasseur P, et al. Ghrelin treatment causes increased food intake and retention of lean body mass in a rat model of cancer cachexia. Endocrinology. 2007;148(6):3004-3012.

30. Dixit VD, Schaffer EM, Pyle RS, et al. Ghrelin inhibits leptin- and activation-induced proinflammatory cytokine expression by human monocytes and T cells. J Clin Invest. 2004;114(1):57-66.

31. Hiura Y, Takiguchi S, Yamamoto K, et al. Effects of ghrelin administration during chemotherapy with advanced esophageal cancer patients: a prospective, randomized, placebo-controlled phase 2 study. Cancer. 2012;118(19):4785-4794.

32. Neary NM, Small CJ, Wren AM, et al. Ghrelin increases energy intake in cancer patients with impaired appetite: acute, randomized, placebocontrolled trial. J Clin Endocrinol Metab. 2004;89(6):2832-2836. 
33. Nagaya N, Moriya J, Yasumura Y, et al. Effects of ghrelin administration on left ventricular function, exercise capacity, and muscle wasting in patients with chronic heart failure. Circulation. 2004;110(24): 3674-3679.

34. Miki K, Maekura R, Nagaya N, et al. Ghrelin treatment of cachectic patients with chronic obstructive pulmonary disease: a multicenter, randomized, double-blind, placebo-controlled trial. PLoS One. 2012; 7(5):e35708

35. Nagaya N, Itoh T, Murakami S, et al. Treatment of cachexia with ghrelin in patients with COPD. Chest. 2005;128(3):1187-1193.

36. Kojima M, Hosoda H, Date Y, Nakazato M, Matsuo H, Kangawa K. Ghrelin is a growth-hormone-releasing acylated peptide from stomach. Nature. 1999;402(6762):656-660.

37. Bowers CY, Momany F, Reynolds GA, Chang D, Hong A, Chang K. Structure-activity relationships of a synthetic pentapeptide that specifically releases growth hormone in vitro. Endocrinology. 1980;106(3): 663-667.

38. Hansen TK, Peschke B, Lau J, Lundt BF, Ankersen M, Watson B, Madsen K, inventors; Novo Nordisk A/S, asignee. Compounds with growth hormone releasing properties. United States patent US 6127391. October 3, 2000.

39. Bednarek MA, Feighner SD, Pong SS, et al. Structure-function studies on the new growth hormone-releasing peptide, ghrelin: minimal sequence of ghrelin necessary for activation of growth hormone secretagogue receptor 1a. J Med Chem. 2000;43(23):4370-4376.

40. Leese PT, Trang JM, Blum RA, de Groot E. An open-label clinical trial of the effects of age and gender on the pharmacodynamics, pharmacokinetics and safety of the ghrelin receptor agonist anamorelin. Clin Pharmacol Drug Dev. 2015;4(2):112-120.

41. Pietra C, Takeda Y, Tazawa-Ogata N, et al. Anamorelin HCl (ONO7643), a novel ghrelin receptor agonist, for the treatment of cancer anorexia-cachexia syndrome: preclinical profile. J Cachexia Sarcopenia Muscle. 2014;5(4):329-337.
42. Northrup R, Kuroda K, Duus EM, et al. Effect of ghrelin and anamorelin (ONO-7643), a selective ghrelin receptor agonist, on tumor growth in a lung cancer mouse xenograft model. Support Care Cancer. 2013; 21(9):2409-2415.

43. Garcia JM, Polvino WJ. Pharmacodynamic hormonal effects of anamorelin, a novel oral ghrelin mimetic and growth hormone secretagogue in healthy volunteers. Growth Horm IGF Res. 2009;19(3):267-273.

44. Garcia JM, Polvino WJ. Effect on body weight and safety of RC-1291, a novel, orally available ghrelin mimetic and growth hormone secretagogue: results of a phase I, randomized, placebo-controlled, multipledose study in healthy volunteers. Oncologist. 2007;12(5):594-600.

45. Garcia JM, Friend J, Allen S. Therapeutic potential of anamorelin, a novel, oral ghrelin mimetic, in patients with cancer-related cachexia: a multicenter, randomized, double-blind, crossover, pilot study. Support Care Cancer. 2013;21(1):129-137.

46. Garcia JM, Boccia RV, Graham CD, et al. Anamorelin for patients with cancer cachexia: an integrated analysis of two phase 2, randomised, placebo-controlled, double-blind trials. Lancet Oncol. 2015;16(1): $108-116$.

47. Takayama K, Katakami N, Yokoyama T, et al. Anamorelin (ONO-7643) in Japanese patients with non-small cell lung cancer and cachexia: results of a randomized phase 2 trial. Support Care Cancer. 2016;24(8): 3495-3505.

48. Temel JS, Abernethy AP, Currow DC, et al. Anamorelin in patients with non-small-cell lung cancer and cachexia (ROMANA 1 and ROMANA 2): results from two randomised, double-blind, phase 3 trials. Lancet Oncol. 2016;17(4):519-531.
Drug Design, Development and Therapy

\section{Publish your work in this journal}

Drug Design, Development and Therapy is an international, peerreviewed open-access journal that spans the spectrum of drug design and development through to clinical applications. Clinical outcomes, patient safety, and programs for the development and effective, safe, and sustained use of medicines are the features of the journal, which

\section{Dovepress}

has also been accepted for indexing on PubMed Central. The manuscript management system is completely online and includes a very quick and fair peer-review system, which is all easy to use. Visit http://www.dovepress.com/testimonials.php to read real quotes from published authors. 